\title{
Ketamine alleviates HMGB1-induced acute lung injury through TLR4 signaling pathway
}

\author{
Dong Xu ${ }^{1, B, C}$, Xang Sun ${ }^{2, A, B}$, Yang Zhang ${ }^{3, E, F}$, Li Ca0 $0^{1, C, D}$ \\ ${ }^{1}$ Department of Anesthesiology, Jinan Central Hospital Affiliated to Shandong University, China \\ ${ }^{2}$ Department of Intensive Care Unit, Jinan Central Hospital Affiliated to Shandong University, China \\ ${ }^{3}$ Department of Anesthesiology, Binzhou People's Hospital, China \\ A - research concept and design; $\mathrm{B}$ - collection and/or assembly of data; $\mathrm{C}$ - data analysis and interpretation; \\ $\mathrm{D}$ - writing the article; $\mathrm{E}$ - critical revision of the article; $\mathrm{F}$ - final approval of the article
}

\section{Address for correspondence \\ Lei Chao}

E-mail: qiechengjing58@163.com

Funding sources

None declared

Conflict of interest

None declared

Received on June 1, 2018

Reviewed on September 8, 2019

Accepted on May 1, 2020

Published online on July 28, 2020

\begin{abstract}
Background. Acute lung injury (ALI) is a common critical respiratory disease that seriously threatens human health. Ketamine has good anti-inflammatory and immune-regulating properties that can delay the lung injury process.
\end{abstract}

Objectives. High mobility group box protein 1 (HMGB1) plays an important role in the occurrence, development and treatment of ALI. Toll-like receptor 4 (TLRA) is the receptor for HMGB1. The aim of this study was to determine the role of the HMGB1 TLR4 signaling pathway in the treatment of ALI using ketamine.

Material and methods. A total of 30 healthy, male, 8-week-old Sprague-Dawley rats were randomly, equally divided into a control group, an lipopolysaccharide (LPS) group and a ketamine group. In order to establish a rat ALI model, $15 \mathrm{mg} / \mathrm{kg}$ of LPS was injected into the femoral veins. Ketamine was intravenously injected $(10 \mathrm{mg} / \mathrm{kg}$ ) into the experimental group rats. The rats were euthanized $24 \mathrm{~h}$ after modeling and lung tissue samples were collected. Western blot was used to test TLR4, MyD88, TRAF-6, LOX-1, and HMGB1 protein expression in the lung tissue. Real-time polymerase chain reaction (RT-PCR) was performed to detect TLR4, MyD88, TRAF-6, LOX-1, and HMGB1 mRNA levels.

Results. Compared with the controls, the LPS group had significantly higher TLR4, MyD88, TRAF-6, LOX-1, and HMGB1 mRNA and protein levels $(p<0.05)$. These levels were significantly lower after ketamine intervention in comparison with the LPS group $(p<0.05)$. A positive correlation was found between TLR4 and HMGB1 expression in the LPS and ketamine groups ( $r=0.952, p<0.001 ; r=0.941, p<0.001)$.

Conclusions. Ketamine attenuates HMGB1-induced ALL, possibly by regulating the TLR4 signaling pathway. Key words: ketamine, acute lung injury, TLR4, HMGB1

Cite as

Xu D, Sun X, Zhang Y, Chao L. Ketamine alleviates HMGB1induced acute lung injury through TLR4 signaling pathway. Adv Clin Exp Med. 2020;29(7):813-817.

doi:10.17219/acem/121936

DOI

10.17219/acem/121936

Copyright

Copyright by Author(s)

This is an article distributed under the terms of the

Creative Commons Attribution 3.0 Unported (CC BY 3.0)

(https://creativecommons.org/licenses/by/3.0/) 


\section{Introduction}

Acute lung injury (ALI) is a type of pulmonary inflammatory reaction which is caused by severe trauma, shock, severe infections, acidosis, and injuries of capillary endothelial cells and alveolar epithelial cells triggered by inflammatory cell cascade. ${ }^{1}$ It may lead to diffuse pulmonary interstitial and alveolar edema, resulting in hypoxia and causing tissue necrosis and dysfunction. Acute lung injury may advance to acute respiratory distress syndrome. It is a common critical disease featuring rapid onset, quick development, poor prognosis, and high mortality. ${ }^{2}$ In recent years, although ALI treatment has achieved certain progress, the mortality of ALI is still higher than $40 \%{ }^{3}$

Ketamine is widely used in clinical intravenous anesthesia. It has anti-inflammatory and immune-regulating functions, and presents a great inhibitory effect which prevents the production of a variety of inflammatory cytokines, the function of neutrophils and the expression of adhesion molecule. ${ }^{4-6}$ Studies have shown that small doses of ketamine can alleviate the symptom of pulmonary edema, ${ }^{7}$ indicating that ketamine has a therapeutic effect on ALI. ${ }^{6,8}$ In addition, a previous study demonstrated that ketamine can improve the blood gas and pulmonary function index of patients with ALI caused by mechanical ventilation. ${ }^{9}$ However, its mechanism has not been fully elucidated. Therefore, this study investigated the mechanism of ketamine in treating ALI in a rat model.

High mobility group box protein 1 (HMGB1) is widely distributed in the nucleus and cytoplasm of all types of cells. The HGMB1 in immune cells translocates from the nucleus to the cytoplasm and is secreted extracellularly under stimulus. ${ }^{10}$ Wang et al. first found in 1999 that HMGB1 was an important inflammatory mediator in sepsis. ${ }^{11}$ It was reported that HMGB1 was also involved in ALI as an important inflammatory factor. ${ }^{12,13}$ Timely blocking the secretion of inflammatory factors is the key to ALI treatment. ${ }^{14,15}$ Thus, inhibiting HMGB1 secretion can delay the lung injury process. Toll-like receptor 4 (TLR4) also plays a critical role in the inflammatory response. As the receptor of HMGB1, the TLR4 signaling pathway plays pro-inflammatory roles. ${ }^{16,17}$ It was revealed that knockdown of the TLR4 gene can alleviate HMGB1induced inflammatory response..$^{18}$ Therefore, this study tested whether molecules related to the TLR4 signaling pathway and HMGB1 expression are involved in the effects of ketamine on treating ALI, aiming to provide a theoretical basis for using ketamine in the clinical treatment of ALI.

\section{Material and methods}

\section{Main instruments and reagents}

Lipopolysaccharide (LPS) was purchased from SigmaAldrich (St. Louis, USA). Ketamine hydrochloride was obtained from Fujian Gutian Pharmaceutical Co., Ltd.
(Ningde, China). A rat HMGB1 ELISA kit was sourced from Shanghai Yaji Biological Technology Co., Ltd. (Shanghai, China), while a rat TLR4 enzyme-linked immunosorbent assay (ELISA) kit was purchased from Shanghai Ricky Biological Technology Co., Ltd. (Shanghai, China). A total protein extraction kit came from BestBio Technologies (Shanghai, China). A Coomassie Brilliant Blue protein detection kit was purchased from MajorBio Technology, Ltd. (Shanghai, China). The SDS-PAGE system, phosphatebuffered saline-Tween (PBST) solution, electrophoresis apparatus, and a GIS-2020D gel image analysis system were obtained from Sigma-Aldrich. HMGB1, TLR4 and GAPDH antibodies came from Abcam (Cambridge, UK). Horseradish peroxidase (HRP)-tagged goat anti-rabbit IgG obtained from Dycent Biotech (Shanghai, China).

\section{Animal modeling}

A total of 30 healthy, male, 8-week-old Sprague Dawley rats (180-220 g) were purchased from the Chinese Academy of Medical Sciences Animal Experiment Center (Beijing, China), and randomly, equally divided into a control group $(\mathrm{n}=10)$ an LPS group $(\mathrm{n}=10)$, and a ketamine group $(\mathrm{n}=10)$. Following the study by Gokcinar et al., $15 \mathrm{mg} / \mathrm{kg}$ of LPS was intravenously injected to establish an ALI model. ${ }^{19}$ Ketamine was intravenously injected $(10 \mathrm{mg} / \mathrm{kg})$ into the ketamine intervention group. An equal amount of normal saline was administered to the controls. The rats were euthanized using $\mathrm{CO}_{2} 24 \mathrm{~h}$ after modeling, and lung tissue samples were collected and stored at $-80^{\circ} \mathrm{C}$.

Rats were used for all experiments, and all procedures were approved by the Animal Ethics Committee of China Meitan General Hospital (Beijing, China).

\section{$\mathrm{PaO} 2$ to $\mathrm{FiO} 2$ ratio}

The arterial blood gases were analyzed using a Bayer Rapidlab 348 Analyzer (Bayer Diagnostics, Leverkusen, Germany) to calculate the ratio of partial pressure of arterial oxygen $(\mathrm{PaO} 2)$ to the percentage of inspired oxygen $(\mathrm{FiO} 2)$.

\section{Real-time PCR}

Tissue RNA was extracted using TRIzol reagent, and the integrity of the RNA was identified using $1 \%$ agarose gel electrophoresis. A total of $1 \mu \mathrm{g}$ of RNA was reversetranscribed to cDNA with a kit (Takara, Kyoto, Japan). The real-time polymerase chain reaction (RT-PCR) reaction system contained $5 \mu \mathrm{L}$ of $2 \times$ SYBR Green Mixture, $0.5 \mu \mathrm{L}$ of cDNA, $0.5 \mu \mathrm{L}$ of Primer $(10 \mu \mathrm{M})$, and $4 \mu \mathrm{L}$ of $\mathrm{ddH}_{2} \mathrm{O}$. The reaction conditions consisted of $10 \mathrm{~min}$ at $95^{\circ} \mathrm{C}$, followed by 40 cycles of $95^{\circ} \mathrm{C}$ for $15 \mathrm{~s}$ and $60^{\circ} \mathrm{C}$ for 60 s. The RT-PCR reaction was performed on a ViiA 7 Real-Time PCR System (Thermo Fisher Scientific, Waltham, USA). Each sample was set in 3 parallel trials. $\beta$-actin was selected as the internal reference. 


\section{Western blot}

Total protein was extracted from the lung tissue and separated using SDS-PAGE. Next, it was transferred to an nitrocellulose (NC) membrane membrane and blocked in 5\% skim milk at room temperature for $2 \mathrm{~h}$. After being washed in PBST 3 times, the membrane was incubated with the primary antibody at $4^{\circ} \mathrm{C}$ overnight. Then, the membrane was incubated with the secondary antibody in $2.5 \%$ skim milk for $60 \mathrm{~min}$. After the chemiluminescence reagent was added, the membrane was developed and analyzed with the GIS-2020D gel image system (Ningbo Sjia Lab Equipment Co.,Ltd, Ningbo, China). The GAPDH gene was selected as the internal reference.

\section{Statistical analysis}

The SPSS v. 19.0 software (IBM Corp., Armonk, USA) was used for the data analysis. Data are presented as means \pm standard deviation (SD). Comparison of the mean values was performed using Student's t-test. Correlation analysis was applied using Pearson analysis. A p-value $<0.05$ was considered statistically significant.

\section{Results}

\section{$\mathrm{PaO2}: \mathrm{FiO} 2$ ratio}

To confirm the success of the ALI model, we performed a gas test to measure the $\mathrm{PaO} 2: \mathrm{FiO} 2$ ratio and found a significantly lower $\mathrm{PaO} 2: \mathrm{FiO} 2$ ratio in the LPS group $(156.1 \pm 21.3)$ than in the control group (475.6 \pm 39.5$)$ $(\mathrm{p}<0.05)$, indicating the successful establishment of an ALI model, which was consistent with the pathological changes of lung as demonstrated by H\&E staining (Fig. 1).

\section{TLR4, MyD88, TRAF-6, LOX-1, and HMGB1 mRNA expression in rat lung tissue}

Real-time PCR was performed to test TLR4, MyD88, TRAF-6, LOX-1, and HMGB1 mRNA expression in the study groups (Table 1). Compared with the control group, the LPS group showed significantly higher TLR4, MyD88, TRAF-6, LOX-1, and HMGB1 mRNA expression $(\mathrm{p}<0.05)$. These levels were notably lower following ketamine intervention in comparison with the LPS group $(\mathrm{p}<0.05)$, but were still higher than those in the control group $(\mathrm{p}<0.05)$.

\section{TLR4, MyD88, TRAF-6, LOX-1, and HMGB1 protein levels in rat lung tissue}

Western blot analysis was performed to detect TLR4, MyD88, TRAF-6, LOX-1, and HMGB1 protein levels, and the findings demonstrate a similar tendency as with mRNA (Table 2 and Fig. 2). The LPS group showed markedly upregulated TLR4, MyD88, TRAF-6, LOX-1, and HMGB1 protein levels compared with the controls $(\mathrm{p}<0.05)$. Ketamine intervention significantly reduced the protein levels, but they were still higher than those in the controls $(\mathrm{p}<0.05)$.

Table 1. mRNA expression levels of TLR4, MyD88, TRAF-6, LOX-1, and HMGB1 in rat lung tissue

\begin{tabular}{|l|c|c|c|c|c|c|}
\hline \multicolumn{1}{|c|}{ Group } & $\mathrm{n}$ & TLR4 & MyD88 & TRAF-6 & HOX-1 \\
\hline Control & 1 & $1.00 \pm 0.21$ & $1.00 \pm 0.22$ & $1.00 \pm 0.18$ & $1.00 \pm 0.19$ \\
\hline LPS & 10 & $3.89 \pm 0.31^{\mathrm{a}}$ & $2.96 \pm 0.28^{\mathrm{a}}$ & $2.45 \pm 0.42^{\mathrm{a}}$ & $1.00 \pm 0.20$ \\
\hline Ketamine + LPS & 10 & $1.58 \pm 0.27^{\mathrm{a}, \mathrm{b}}$ & $2.02 \pm 0.25^{\mathrm{a}, \mathrm{b}}$ & $1.85 \pm 0.32^{\mathrm{a}, \mathrm{b}}$ & $1.37 \pm 0.36^{\mathrm{a}, \mathrm{b}}$ \\
\hline
\end{tabular}

${ }^{a} p<0.05$, compared with the controls; ${ }^{b} p<0.05$, compared with the LPS group; LPS - lipopolysaccharide; $n$ - number.

control

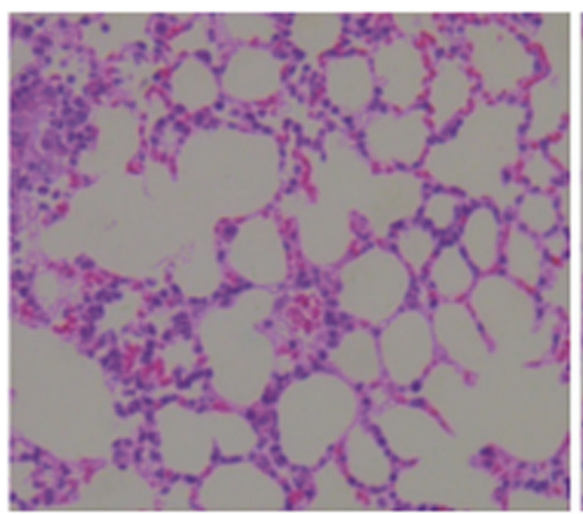

LPS

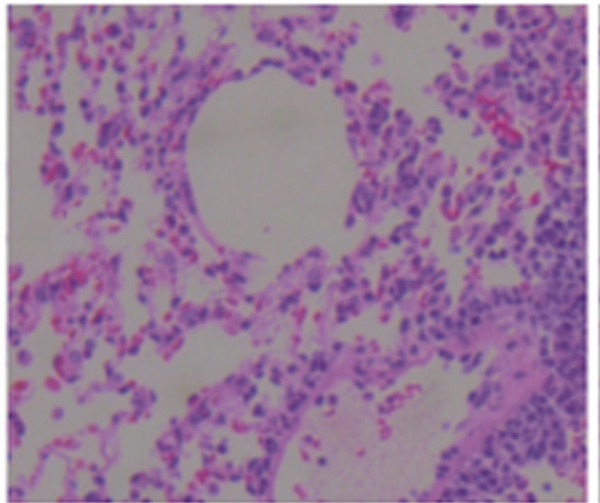

ketamine + LPS

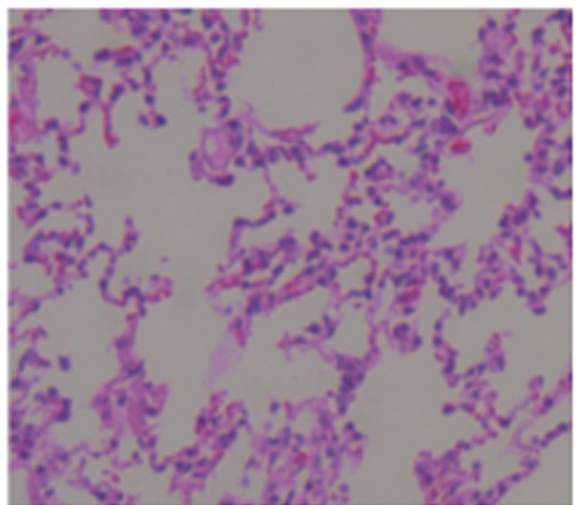

Fig. 1. Histological changes of acute lung injury. In the control group, the pulmonary alveolar, interstitial and bronchial vessels were normal. However, the lung tissues in rats treated with LPS were damaged, with obvious pulmonary edema, positive cell infiltration and visible focal necrosis. Rats receiving ketamine displayed a thick alveolar wall, alleviated hyperemia, reduced exudation in the pulmonary alveolar cavity, and relieved infiltration of inflammatory cells 
Table 2. Protein levels of TLR4, MyD88, TRAF-6, LOX-1, and HMGB1 in rat lung tissue

\begin{tabular}{|l|c|c|c|c|c|c|}
\multicolumn{1}{|c|}{ Group } & $\mathrm{n}$ & TLR4 & MyD88 & TRAF-6 & LOX-1 \\
\hline Control & 10 & $0.81 \pm 0.14$ & $0.58 \pm 0.12$ & $0.71 \pm 0.14$ & $0.51 \pm 0.09$ \\
\hline LPS & 10 & $1.20 \pm 0.10^{\mathrm{a}}$ & $0.72 \pm 0.11^{\mathrm{a}}$ & $0.97 \pm 0.13^{\mathrm{a}}$ & $1.00 \pm 0.11^{\mathrm{a}}$ \\
\hline Ketamine + LPS & 10 & $0.95 \pm 0.12^{\mathrm{a}, \mathrm{b}}$ & $0.62 \pm 0.10^{\mathrm{a}, \mathrm{b}}$ & $0.81 \pm 0.10^{\mathrm{a}, \mathrm{b}}$ & $0.72 \pm 0.12^{\mathrm{a}, \mathrm{b}}$ \\
\hline
\end{tabular}

${ }^{a} p<0.05$, compared with the controls; ${ }^{b} p<0.05$, compared with the LPS group; LPS - lipopolysaccharide; $n$ - number.

\section{TLR4 and HMGB1 protein level correlation analysis in rat lung tissue}

Pearson analysis was performed to test TLR4 and HMGB1 protein correlation in the rat lung tissue (Fig. 3). The results show that there was a positive correlation between TLR4 and HMGB1 expression in the LPS and ketamine groups $(\mathrm{r}=0.952, \mathrm{p}<0.001 ; \mathrm{r}=0.941, \mathrm{p}<0.001)$.

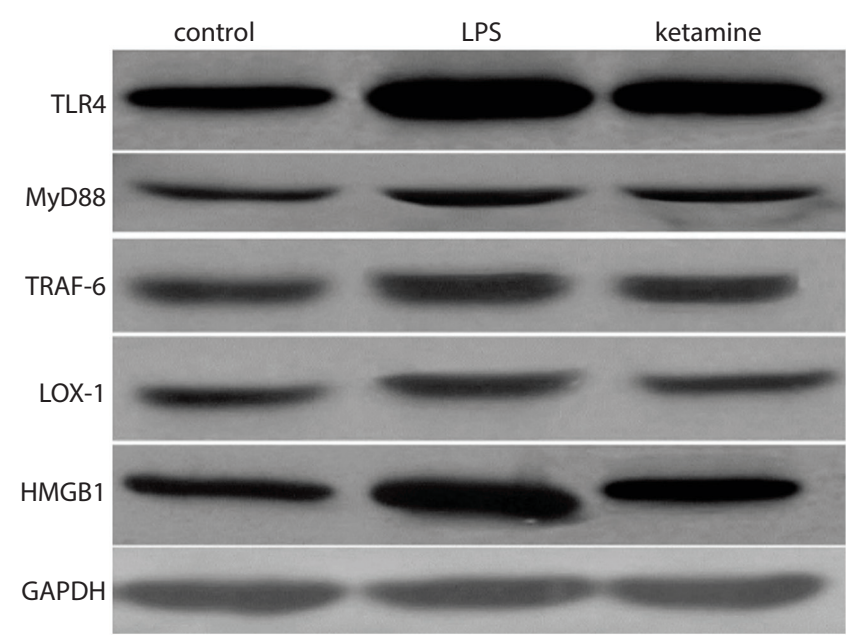

Fig. 2. Western blot analysis of protein levels in lung tissue among the 3 groups. The LPS group showed markedly upregulated protein levels of TLR4, MyD88, TRAF-6, LOX-1, and HMGB1 compared with the controls; ketamine intervention obviously reduced these levels, but they were still higher than in the controls

\section{Discussion}

Ketamine, a derivative of phencyclidine, is a noncompetitive N-methyl-D-aspartic acid (NMDA) receptor antagonist and is usually used in anesthesia. Ketamine can suppress the release of inflammatory factors, such as tumor necrosis factor $\alpha$ (TNF- $\alpha$ ), interleukin (IL)- 6 and IL-8. ${ }^{20}$ It was found that ketamine also can inhibit the TLR4 signaling pathway. ${ }^{21,22}$ It was reported that ketamine can delay the progress of ALI. In addition, HMGB1 expression is associated with the occurrence of ALI, and inhibiting HMGB1 expression can ameliorate ALI. TLR4 is the receptor for HMGB1, so suppressing the TLR/NF-kB signaling pathway can restrain ALI inflammation. ${ }^{23}$ Therefore, we have reasons to believe that ketamine may attenuate HMGB1-induced ALI by regulating the TLR4 signaling pathway.

This study used LPS to establish a rat ALI model and tested molecules related to HMGB1 and the TLR4 signaling pathway in lung tissue. The results showed that the TLR4, MyD88, TRAF-6, LOX-1, and HMGB1 mRNA and protein levels were significantly higher in the LPS group than in the control group. This suggests that both HMGB1 and the TLR4 signaling pathway are involved in ALI. Wang et al. demonstrated that HMGB1 was clearly upregulated in ALI, further proving that HMGB1 plays an important role in this disease. ${ }^{24}$ Abdelmageed et al. reported that the TLR4 signaling pathway was involved in the occurrence of ALI, further confirming the critical role of the TLR4 signaling pathway in ALI. ${ }^{25}$

As TLR4 siRNA can alleviate HMGB1-induced inflammation, ${ }^{17}$ it appears that ketamine may attenuate HMGB1induced ALI by regulating the TLR4 signaling pathway. This also demonstrates that clinical drug therapy can inhibit inflammation and delay the ALI process by regulating the TLR4 signaling pathway. Similarly, Qin et al. also discovered that ketamine can downregulate HMGB1 and TLR4 protein levels in bronchoalveolar lavage fluid and lung tissue. ${ }^{26}$ In the present study, we found that ketamine intervention significantly decreased TLR4,
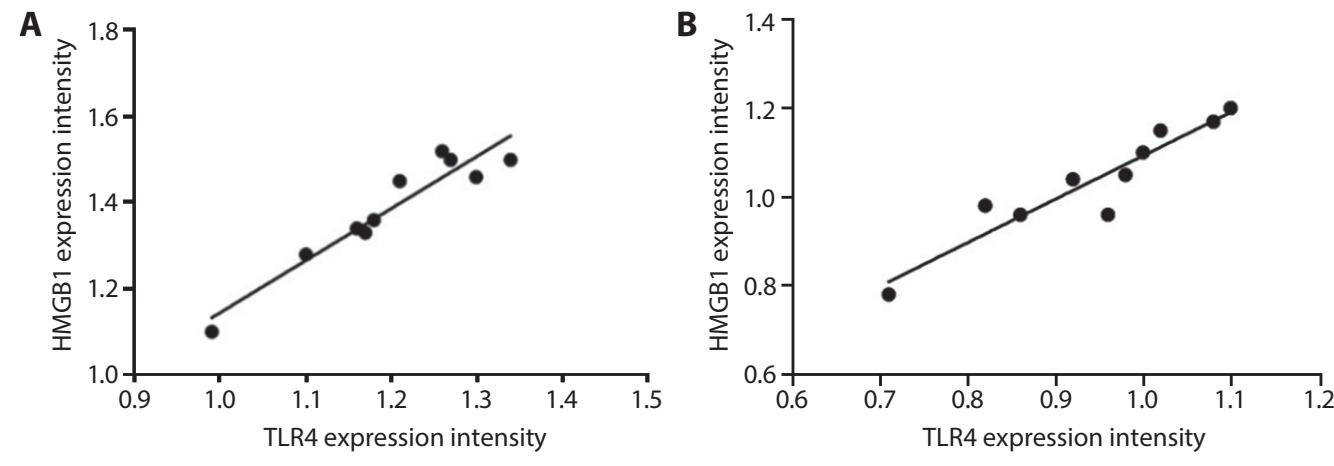

Fig. 3. Correlative analysis of TLR4 and HMGB1 level in rat lung tissue. There was a positive correlation between TLR4 and HMGB1 expression in the LPS (A) and ketamine + LPS (B) groups $(r=0.952, p<0.001 ; r=0.941$, $p<0.001)$ 
MyD88, TRAF-6, and LOX-1 mRNA and protein expression in comparison with the LPS group. In addition, TLR4 and HMGB1 expression displayed a positive correlation. Our study suggests that ketamine ameliorates ALI, possibly by regulating the TLR4/HMGB1 signaling pathway, thus exerting anti-inflammatory effects. However, future studies are required to confirm this finding.

The mechanism of ALI is complicated, while ketamine may also have an intricate network in treating ALI. This study only found that ketamine may attenuate HMGB1induced ALI by regulating the TLR4 signaling pathway. Further investigation is needed in order to clarify its specific mechanism.

\section{ORCID iDs}

Lei Chao (1) https://orcid.org/0000-0001-8247-897X

Dong Xu (i) https://orcid.org/0000-0002-5199-1110

Xang Sun (1) https://orcid.org/0000-0002-3338-5432

Yang Zhang (1) https://orcid.org/0000-0002-4141-6630

\section{References}

1. Kao RL, XuX, Xenocostas A, et al. Induction of acute lung inflammation in mice with hemorrhagic shock and resuscitation: Role of HMGB1. J Inflamm (Lond). 2014;11(1):30.

2. Luh SP, Chiang $\mathrm{CH}$. Acute lung injury/acute respiratory distress syndrome (ALI/ARDS): The mechanism, present strategies and future perspectives of therapies. J Zhejiang Univ Sci B. 2007;8(1):60-69.

3. Villar J, Sulemanji D, Kacmarek RM. The acute respiratory distress syndrome: Incidence and mortality, has it changed? Curr Opin Crit Care. 2014;20(1):3-9.

4. Berger MM, Pitzer B, Zugel S, et al. Alveolar but not intravenous S-ketamine inhibits alveolar sodium transport and lung fluid clearance in rats. Anesth Analg. 2010;111(1):164-170.

5. Yang CL, Chen CH, Tsai PS, Wang TY, Huang CJ. Protective effects of dexmedetomidine-ketamine combination against ventilator-induced lung injury in endotoxemia rats. J Surg Res. 2011;167(2):e273-e281.

6. Yang CH, Tsai PS, Wang TY, Huang CJ. Dexmedetomidine-ketamine combination mitigates acute lung injury in haemorrhagic shock rats. Resuscitation. 2009;80(10):1204-1210.

7. Shen $\mathrm{H}$, Jin L, Zhuang X, Zhou Y. A single small dose of ketamine prevents lung injury following hepatic ischemia-reperfusion in rabbits. J Chin Med Assoc. 2011;74(8):350-356.

8. Erdem MK, Yurdakan G, Yilmaz-Sipahi E. The effects of ketamine, midazolam and ketamine/xylazine on acute lung injury induced by alpha-naphthylthiourea in rats. Adv Clin Exp Med. 2014;23(3):343-351.

9. Wang WF, Liu S, Xu B. A study of the protective effect and mechanism of ketamine on acute lung injury induced by mechanical ventilation. Eur Rev Med Pharmacol Sci. 2017;21(6):1362-1367.
10. Dange RB, Agarwal D, Teruyama R, Francis J. Toll-like receptor 4 inhibition within the paraventricular nucleus attenuates blood pressure and inflammatory response in a genetic model of hypertension. J Neuroinflammation. 2015;12:31.

11. Wang $\mathrm{H}$, Bloom $\mathrm{O}$, Zhang $\mathrm{M}$, et al. HMG-1 as a late mediator of endotoxin lethality in mice. Science. 1999;285(5425):248-251.

12. Zhou M, Zhang Y, Chen X, et al. PTEN-Foxo1 signaling triggers HMGB1mediated innate immune responses in acute lung injury. Immunol Res. 2015;62(1):95-105.

13. Entezari $M$, Javdan $M$, Antoine DJ, et al. Inhibition of extracellular HMGB1 attenuates hyperoxia-induced inflammatory acutelung injury. Redox Biol. 2014;2:314-322.

14. Haitsma JJ, Lachmann B, Papadakos PJ. Additives in intravenous anesthesia modulate pulmonary inflammation in a model of LPS-induced respiratory distress. Acta Anaesthesiol Scand. 2009;53(2):176-182.

15. Liu XX, Yu DD, Chen MJ, et al. Hesperidin ameliorates lipopolysaccharide-induced acute lung injury in mice by inhibiting HMGB1 release. Int Immunopharmacol. 2015;25(2):370-376.

16. Chen $Y$, Huang $X J, Y u ~ N$, et al. HMGB1 contributes to the expression of $\mathrm{P}$-glycoprotein in mouse epileptic brain through toll-like receptor 4 and receptor for advanced glycation end products. PLoS One. 2015;10(10):e0140918.

17. Li G, Wu X, Yang L, et al. TLR4-mediated NF-kappaB signaling pathway mediates HMGB1-induced pancreatic injury in mice with severe acute pancreatitis. Int J Mol Med. 2016;37(1):99-107.

18. Lai CH, Wang KC, Lee FT, et al. Toll-like receptor 4 is essential in the development of abdominal aortic aneurysm. PLoS One. 2016; 11(1):e0146565.

19. Gokcinar D, Ergin V, Cumaoglu A, Menevse A, Aricioglu A. Effects of ketamine, propofol, and ketofol on pro-inflammatory cytokines and markers of oxidative stress in a rat model of endotoxemiainduced acute lung injury. Acta Biochim Pol. 2013;60(3):451-456.

20. Lange $M$, Broking $K$, van Aken $H$, Hucklenbruch $C$, Bone HG, Westphal $\mathrm{M}$. Role of ketamine in sepsis and systemic inflammatory response syndrome [in German]. Anaesthesist. 2006;55(8):883-891.

21. Wu Y, Li W, Zhou C, et al. Ketamine inhibits lipopolysaccharideinduced astrocytes activation by suppressing TLR4/NF-kB pathway. Cell Physiol Biochem. 2012;30(3):609-617.

22. Yu M, Shao D, Yang R, Feng X, Zhu S, Xu J. Effects of ketamine on pulmonary inflammatory responses and survival in rats exposed to polymicrobial sepsis. J Pharm Pharm Sci. 2007;10(4):434-442.

23. Tianzhu Z, Shumin W. Esculin inhibits the inflammation of LPSinduced acute lung injury in mice via regulation of TLR/NF-kappaB pathways. Inflammation. 2015;38(4):1529-1536.

24. Wang SY, Li ZJ, Wang X, Li WF, Lin ZF. Effect of ulinastatin on HMGB1 expression in rats with acute lung injury induced by sepsis. Genet Mol Res. 2015;14(2):4344-4353.

25. Abdelmageed ME, El-Awady MS, Suddek GM. Apocynin ameliorates endotoxin-induced acute lung injury in rats. Int Immunopharmacol. 2016;30:163-170.

26. Qin MZ, Gu QH, Tao J, et al. Ketamine effect on HMGB1 and TLR4 expression in rats with acute lung injury. Int J Clin Exp Pathol. 2015; 8(10):12943-12948. 